\title{
Location of Faults in Power Transmission Lines Using the ARIMA Method
}

\author{
Danilo Pinto Moreira de Souza ${ }^{1}$, Eliane da Silva Christo ${ }^{1, *}$ (D) and Aryfrance Rocha Almeida ${ }^{2}$ \\ 1 Computational Modeling in Science and Technology (MCCT), Fluminense Federal University (UFF), \\ Volta Redonda 21941-916, Brazil; danilopms@id.uff.br \\ 2 Technology Center, Federal University of Piauí (UFPI), Teresina 60455-760, Brazil; aryfrance@ufpi.edu.br \\ * Correspondence: elianechristo@id.uff.br; Tel.: +55-24-2107-3510
}

Received: 11 August 2017; Accepted: 6 October 2017; Published: 13 October 2017

\begin{abstract}
One of the major problems in transmission lines is the occurrence of failures that affect the quality of the electric power supplied, as the exact localization of the fault must be known for correction. In order to streamline the work of maintenance teams and standardize services, this paper proposes a method of locating faults in power transmission lines by analyzing the voltage oscillographic signals extracted at the line monitoring terminals. The developed method relates time series models obtained specifically for each failure pattern. The parameters of the autoregressive integrated moving average (ARIMA) model are estimated in order to adjust the voltage curves and calculate the distance from the initial fault localization to the terminals. Simulations of the failures are performed through the ATPDraw ${ }^{\circledR}(5.5)$ software and the analyses were completed using the RStudio ${ }^{\circledR}$ (1.0.143) software. The results obtained with respect to the failures, which did not involve earth return, were satisfactory when compared with widely used techniques in the literature, particularly when the fault distance became larger in relation to the beginning of the transmission line.
\end{abstract}

Keywords: transmission line; fault localization; time series; ARIMA; discrete wavelet transformer

\section{Introduction}

The behavior of the electricity sector is directly related to economic factors such as Gross Domestic Product (GDP). In this manner, the demand for electricity can be seen as a "thermometer" of the market. As such, growth of the economy as well as increases in purchasing power and quality of life must be accompanied by improvements in the power system, with the objective being compliance with current and future situations. The transportation of electric energy is carried out by means of transmission lines (TLS) which, because they span long distances and are present in great quantity, make the electric power system (EPS) more susceptible to perturbations which are caused mainly by natural phenomena, in particular atmospheric discharges. In the EPS , faults may occur in various components, among which TLs may be the most susceptible elements, especially considering their physical dimensions, functional complexity and the environment they are in, thus presenting greater difficulties in terms of maintenance and monitoring [1].

Keeping in mind the importance of having an electrical system where continuity, compliance, flexibility, and maintainability are observed and guaranteed, we have sought to improve and innovate with respect to techniques used in the protection and supervision equipment of the EPS, while also providing for the expansion of the electric sector and maintenance of system operation quality [2]. The development and improvement of algorithms that allow the analysis and diagnosis of failures in power systems can have an important economic impact, both for power utilities and consumers, as they enable the continuity and reliability of the electric sector. Intelligent, autonomous, online systems have been developed and applied to a significant degree to deal with this type of problem, since they enable fast and accurate diagnosis without the need for human intervention. 
The transient voltage and current components are based on the charge of the capacitances of the faultless phases and the discharges of the fault phases. Transients can be detected in almost all occurrences of failures that require the functioning of the circuit breaker. The characteristics of transient phenomenon can be used in relay protection systems and in the location of faults. This technique is satisfactory when compared to techniques already used, such as the theory of traveling wave $[3,4]$, and techniques that use the calculation of fault impedance [5-7]. The comparison is accomplished through the application of these two methods to several transient signals of various situations of simulated faults in a computational environment. The discrete wavelet transform (DWT) is used to decouple sinusoidal signals from the network and transient signals from faults. The technique is widely used for this purpose and has been demonstrated in the literature, with proven efficacy. For the decoupling of Fourier series, signals can be used very simply, although better results are obtained with more sophisticated methods such as DWT [8,9]. Unlike the Fourier analysis, which provides a global representation of the signal, the wavelet transform provides a local representation (in time and frequency) of a particular signal. This "location" in time allows disturbances in signals to be detected as soon as they begin [10].

The objective of this study is, through time series techniques, to model fault voltage data and thereby locate faults in transmission lines. The coefficients of autoregressive integrated moving average (ARIMA) models have different values depending on where the faults occur on the lines. When traveling waves are used, the main problem is to find the second reverse traveler wave from different disturbance signals [11]. Thus, with a database with different simulated situations, it is possible to adjust curves according to models and calculate fault distances for various situations.

\section{Simulated Transmission Line}

An EPS consists of power plants (hydroelectric, thermoelectric, thermonuclear, alternative sources, and small power plants), TLs (composed of towers, cables, and lifting and lowering substations), and end transmission lines (consisting of transformers, poles and cables and consumption measures). This complex system can involve hundreds or even thousands of kilometers, as is the case of Brazil, for example. Table 1 shows the statistical data in percentages for fault occurrences in the EPS components. Approximately 50\% of absences occur in overhead lines [12]. In the Brazilian electricity system, the transmission lines represent $68 \%$ of the absences in the network [13].

Table 1. Percentage of absences for equipment in the electric power system (EPS).

\begin{tabular}{cc}
\hline Type of Equipment & Percentage Total \\
\hline Aerial lines & 50 \\
Underground cables & 9 \\
Transformers and reactors & 10 \\
Power generators & 7 \\
Circuit breakers & 12 \\
Control equipment and transformers for instruments & 12 \\
\hline
\end{tabular}

The numbers shown in the Table 1 show the importance of more closely monitoring the TLs of an EPS, emphasizing the importance of this study. Therefore, the JMARTI [14] model is used to implement a transmission line in ATPDraw ${ }^{\circledR}(5.5)$ software. The simulated line has an extension of $200 \mathrm{~km}$, nominal voltage of $500 \mathrm{kV}$, and fundamental frequency of $60 \mathrm{~Hz}$, with distributed parameters dependent on the frequency and perfectly transposed in their totality [15].

Figure 1a shows a diagram where the position of the short circuit with respect to the generating terminal can be varied along the line. The monitoring of the voltage signal is performed at the same terminal. The distance $d$ is the variable of interest in this study. 


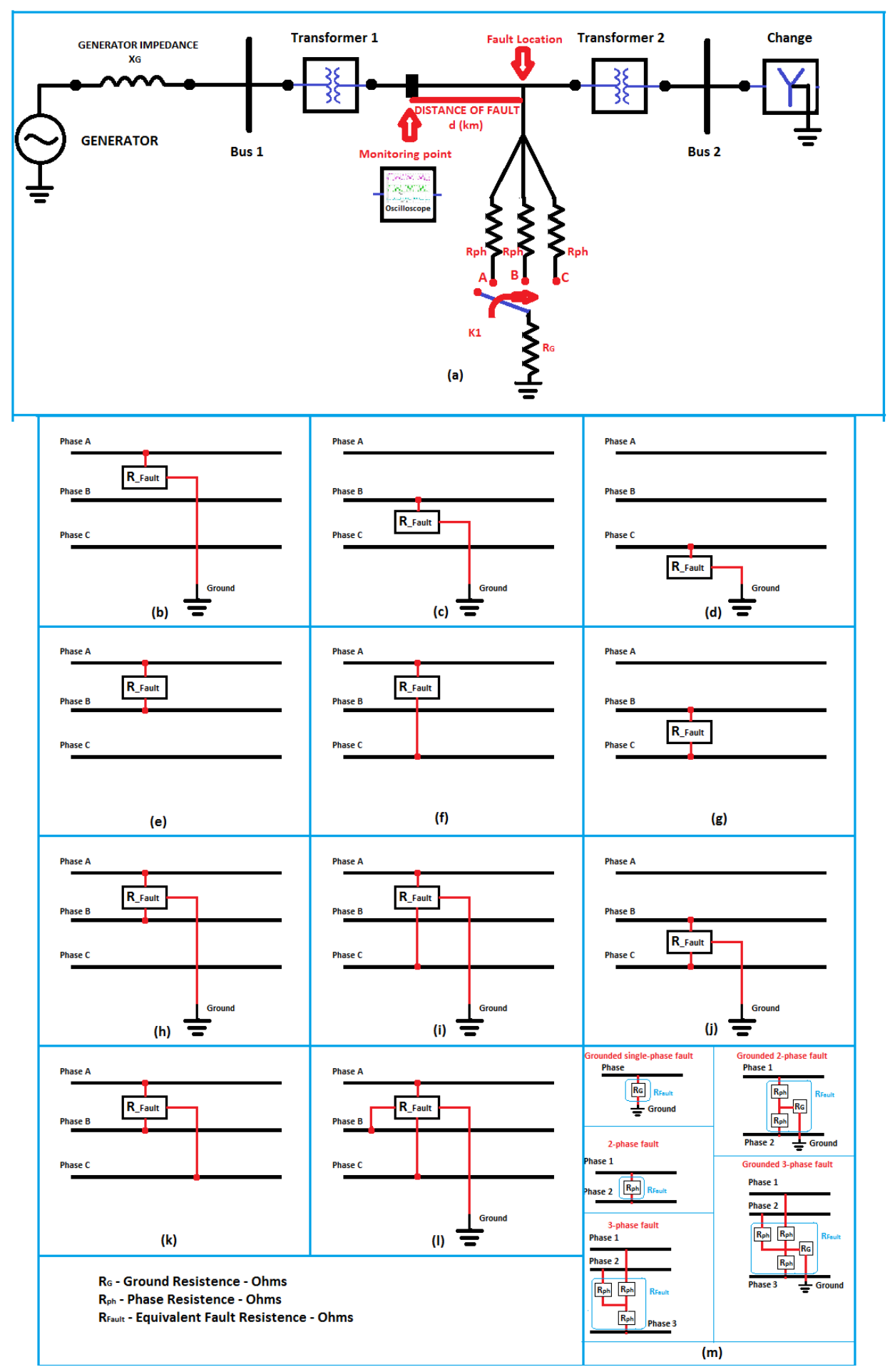

Figure 1. Simulated line topology in the $A T P^{\circledR}$ software. Fault situations for a three-phase system.

All fault settings for a three-phase system are also shown. Situations of single-phase faults: Figure $1 \mathrm{~b}-\mathrm{d}$. Situations of biphasic faults: Figure 1e-g. Situations of grounded biphasic faults: Figure $1 \mathrm{~h}-\mathrm{j}$. Situation of three-phase fault: Figure 1k. Situations of grounded three-phase fault: Figure 11. Settings of phase resistors $R_{p} h$ and ground resistance $R_{G}$ : Figure $1 \mathrm{~m}$.

Table 2 shows all situations of simulated faults with variations of the fault type (elements involved are phases $A, B, C$ and ground $G$ ), signal sampling, line fault position, fault resistance, and incident angle of the disturbance. 
Table 2. Situations of simulated faults.

\begin{tabular}{|c|c|c|c|c|c|}
\hline Fault & $\begin{array}{c}\text { Data Sampling } \\
(\mathrm{kHz})\end{array}$ & $\begin{array}{l}\text { Location } \\
d(\mathrm{~km})\end{array}$ & Failure Resistance $(\Omega)$ & Angle of Incidence $\theta\left({ }^{\circ}\right)$ & $\begin{array}{c}\text { Fault } \\
\text { Situations }\end{array}$ \\
\hline$A-G$ & 200 & $10 ; 45 ; 84 ; 155$ & $20 ; 50 ; 80 ; 120 ; 150 ; 180 ; 200 ; 240$ & $0 ; 45 ; 90 ; 135 ; 180 ; 225 ; 270 ; 315$ & 256 \\
\hline$C-G$ & 200 & $10 ; 45 ; 84 ; 155$ & $20 ; 50 ; 80 ; 120 ; 150 ; 180 ; 200 ; 240$ & $0 ; 45 ; 90 ; 135 ; 180 ; 225 ; 270 ; 315$ & 256 \\
\hline$A-B$ & 200 & $10 ; 45 ; 84 ; 155$ & $20 ; 50 ; 80 ; 120 ; 150 ; 180 ; 200 ; 240$ & $0 ; 45 ; 90 ; 135 ; 180 ; 225 ; 270 ; 315$ & 256 \\
\hline$A-C$ & 200 & $10 ; 45 ; 84 ; 155$ & $20 ; 50 ; 80 ; 120 ; 150 ; 180 ; 200 ; 240$ & $0 ; 45 ; 90 ; 135 ; 180 ; 225 ; 270 ; 315$ & 256 \\
\hline$A-C-G$ & 200 & $10 ; 45 ; 84 ; 155$ & $20 ; 50 ; 80 ; 120 ; 150 ; 180 ; 200 ; 240$ & $0 ; 45 ; 90 ; 135 ; 180 ; 225 ; 270 ; 315$ & 256 \\
\hline$B-C-G$ & 200 & $10 ; 45 ; 84 ; 155$ & $20 ; 50 ; 80 ; 120 ; 150 ; 180 ; 200 ; 240$ & $0 ; 45 ; 90 ; 135 ; 180 ; 225 ; 270 ; 315$ & 256 \\
\hline$A-B-C$ & 200 & $10 ; 45 ; 84 ; 155$ & $20 ; 50 ; 80 ; 120 ; 150 ; 180 ; 200 ; 240$ & $0 ; 45 ; 90 ; 135 ; 180 ; 225 ; 270 ; 315$ & 256 \\
\hline
\end{tabular}

\section{Theory of Traveling Waves}

Disturbances occur in the transmission line of electric power, and are caused by a variety of electromagnetic phenomena such as atmospheric discharges. Sudden changes occur in the conditions of the electrical circuits that make up the transmission system, causing a redistribution of energy with the purpose of finding a new break-even point. Thus, traveling waves refer to the propagation of energy over a system. This energy is distributed by the system in its circuit elements, capacitors and inductors [16].

The propagation of traveling waves always occurs in the direction of all the terminals of the transmission line and causes the electrical transients perceived by the protection relays and other automation and control devices located in the operating centers of the system [16]. If any variation occurs on one terminal of a power transmission line, the other terminal will only feel the variation occurring when the wave travels the entire length of the line [17].

The remote terminal of the transmission line cannot influence the decisions about the system until the wave has traveled from the source of the local terminal to the remote terminal where, through its interaction with the transmission line, a response is produced that travels from back to the local source. In this way, electrical signals tend to propagate back and forth, like traveling waves, usually dissipating energy with losses in the material [17].

The traveling wave theory allows for definition of the reflection and refraction coefficients of the traveling wave in discontinuities as well as the wave propagation velocity and the transmission line surge impedance. It is noteworthy that during propagation along the line, traveling waves are attenuated mainly by resistive and leakage losses and may still suffer distortions in their waveform [18].

In order for the transient behavior of an electromagnetic wave on a transmission line to be adequately represented, it is necessary that the line parameters be evenly distributed over its length, since only this representation allows the theory of the traveling waves to be used to analyze the propagation of these electromagnetic phenomena in it [19].

It is important to note that transmission line models in which the parameters are constant are not adequate for simulation of the transmission line response over a large range of frequencies that are present in the signals during transient conditions [14]. Despite this, in practice, constant frequency distributed line models provide satisfactory results and are used in several transient studies in power systems, according to the Alternative Transient Program Rule Book [16].

The reflections and refractions of the waves that travel on the transmission lines are the result of discontinuities in the course of the wave. These discontinuities can not be caused by terminal impedances, short circuits, or circuit breakers.

In order to monitor the propagation time of the generated wave fronts, only the peaks of these waves are followed. This restriction to only a few points greatly facilitates the monitoring of this data. The lattice diagram shown in Figure 2 is a summary of the above because it focuses only on the propagation times between the point of origin of the fault and the terminals of the line. 


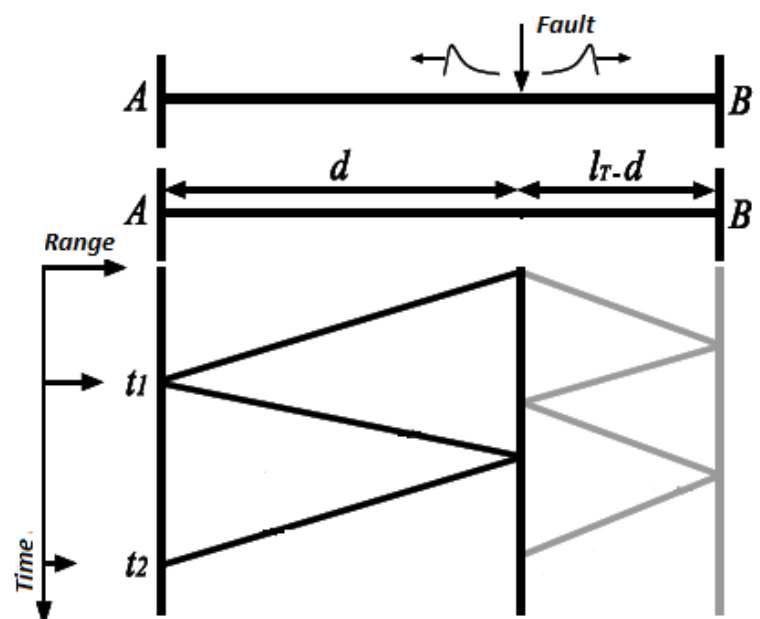

(a)

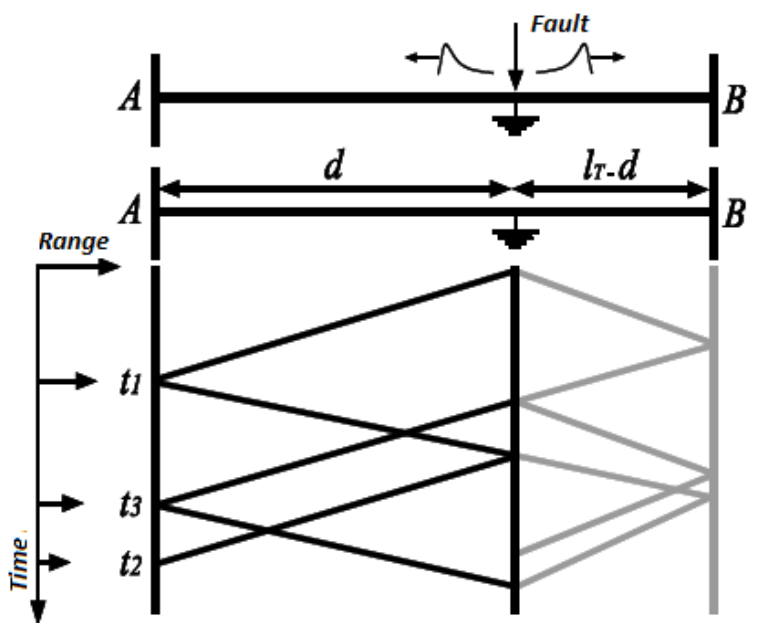

(b)

Figure 2. Peak propagation time. $A$ : Monitoring terminal; $B$ opposite terminal; $d$ : fault distance; $l_{T}$ : line length; $t_{1}$ and $t_{2}$ : propagation times of wave fronts; $t_{3}$ : refracted wave propagation time. (a) Ground fault; (b) Fault without ground [15].

The propagation time of a wave peak between its origin and the monitoring terminal depends on the line length to be traveled by the wave and the propagation speed of this wave. Its propagation speed is dependent on the inductance and capacitance of the line with $v=\frac{1}{\sqrt{L C}}$. However, this value is sufficiently near the rate of light propagation in the vacuum, and can be considered as $v=3 \times 10^{5} \frac{\mathrm{km}}{\mathrm{s}}$. In Figure 2a for example, the distance $d$ can be calculated as shown in Equation (1). In Figure 2b one must take into account the refracted wave of the other part of the transmission line. Thus, the calculation is performed according to Equation (2).

$$
\begin{gathered}
d=\frac{\left(t_{2}-t_{1}\right) v}{2} \\
d=l_{T}-\frac{\left(t_{3}-t_{1}\right) v}{2}
\end{gathered}
$$

where $l_{T}$ is the line length in kilometers; and $d$ is the length between the fault point and the terminal.

\section{Wavelet Transform}

The wavelet transform is a linear operation that decomposes a signal into different scales with different levels of resolution. The wavelet transform of the signal $f(t) C W T$ is defined by [10]:

$$
\operatorname{CWT}_{f}^{\Psi}(a, b)=\int_{-\infty}^{\infty} f(t) * \Psi_{a, b}(t) d t
$$

where $\Psi_{a, b}(t)$ is a daughter wavelet, defined as [20]:

$$
\Psi_{a, b}(t)=\frac{1}{\sqrt{a}} \psi\left(\frac{t-b}{a}\right) ; a \in \mathbf{R}^{+} e b \in \mathbf{R}
$$

In turn, $\Psi(t)$ is the chosen mother wavelet, $a$ is the scaling factor, and $b$ is the shift factor.

For computational use of CWT it is necessary to have discrete parameters of $a$ and $b$. In the discrete case, the scaling and shift factors are represented as Equations (5) and (6) [21]: 


$$
\begin{array}{r}
a=a_{0}^{m} \\
b=n b_{0} a_{0}^{m} \\
m, n \in \mathbf{Z} ; a_{0} \geq 1 ; b_{0} \neq 0
\end{array}
$$

Although the result of Equation (3) is a finite set of coefficients, it is still a continuous representation of the wavelet transform. When the function to be analyzed is given by discrete values $f(k)$, then we must use the discrete wavelet transform DWT defined by [10]:

$$
\begin{array}{r}
D W T_{f}^{\Psi} m, n=a_{0}{ }^{-\frac{m}{2}} \sum_{k} x[k] \Psi\left[a_{0}{ }^{-m} k-n b_{0}\right] \\
a_{0}>1 ; b_{0} \neq 0
\end{array}
$$

\section{Time Series Models}

A time series is any set of observations ordered in time, where each value has attached to itself an indicator of the time in which this value occurred or was observed [22]. According to [23], a time series is constructed when one an interest in:

- Investigating the generating mechanism of the time series;

- Making forecasts of future values of the series;

- Describing only the behavior of the series;

- Searching for relevant periodicities in the data.

A stochastic model that can be extremely useful in representing certain practically occurring series is the autoregressive model. In this model, the current value of the process is expressed as a finite linear aggregate of previous process values and the random shock $a t$. Let us say the values of a process with moments by equally spaced times are $(t, t-1, t-2, \cdots)$ by $\left(Z_{t}, Z_{t-1}, Z_{t-2}, \cdots\right)$. Also, let $\bar{Z}_{t}=Z_{t}-\mu$ be the series of muf deviations. Then, Equation (9) is called an autoregressive $(A R(p))$ process of order $p$.

$$
\begin{array}{r}
\bar{Z}_{t}=\phi_{1} Z_{t-1}+\phi_{2} Z_{t-2}+\cdots+\phi_{p} Z_{t-p}+a_{t} \\
\bar{Z}=\phi_{1} \bar{Z}_{1}+\phi_{2} \bar{Z}_{2}+\cdots+\phi_{p} \bar{Z}_{p}+a
\end{array}
$$

Through the autoregressive operator $B$ given by $\phi(B)=1-\phi_{1} B-\phi_{2} B^{2}-\cdots-\phi_{p} B^{p}$, the autorregressive model in Equation (9) may be written economically as

$$
\phi(B) \bar{Z}_{t}=a_{t}
$$

Another kind of model, of great practical importance in the representation of observed time series is the finite moving average (MA) process, where $\bar{z}_{t}$ is linearly dependent on the finite number $q$ of previous $a^{\prime}$ s. Thus, Equation (10) is called a moving average $M A(q)$.

$$
\bar{Z}_{t}=a_{t}-\theta_{1} a_{t-1}-\theta_{2} a_{t-2}-\cdots-\theta_{q} a_{t-q}
$$

In the same way, we have a moving average operator defined by $\theta(B)=1-\theta_{1} B-\theta_{2} B^{2}-\cdots-$ $\theta_{q} B^{q}$. The moving average model may be written as Equation (11).

$$
\bar{Z}_{t}=\theta(B) a_{t}
$$

The union of the autoregressive model of order $p$ with the moving average model of order $q$ can sometimes benefit the assembly of the time series. This leads to the mixed autoregressive-moving average ARMA $(p, q)$ model:

$$
\bar{Z}_{t}=\phi_{1} \bar{Z}_{t-1}+\cdots+\phi_{p} \bar{Z}_{t-p}+a_{t}-\theta_{1} a_{t-1}-\cdots-\theta_{q} a_{t-q}
$$


Equation (12) can be written with the $B$ operator.

$$
\phi(B) \bar{Z}_{t}=\theta(B) a_{t}
$$

In some cases, it is necessary to make a distinction between the terms of the series to exclude trends, in accordance with Equation (14). The result is an ARIMA $(p, d, q)$ model, where the term I expresses a differentiation of order $d$.

$$
\phi(B) W_{t}^{d}=\theta(B) a_{t}
$$

where $W_{t}^{d}$ are differentiations on the terms of series $Z$ shown in Equation (15).

$$
\begin{array}{r}
W_{t}=\Delta \bar{Z}_{t}=\bar{Z}_{t}-\bar{Z}_{t-1} \\
W_{t}^{d}=\Delta^{d} \bar{Z}_{t}
\end{array}
$$

When $W_{t}$ presents deterministic seasonal behavior of period s, a model that can be used is shown in Equation (16).

$$
\phi(B) \Phi\left(B^{s}\right)\left(\Delta_{s}\right)^{D}(\Delta)^{d} Z_{t}=\theta(B) \Theta\left(B^{s}\right) a_{t}
$$

where $\Phi\left(B^{s}\right)=1-\Phi_{1} B^{s}-\cdots-\Phi_{P} B^{s P}$ is the seasonal autoregressive operator of $P$ order; $\Theta\left(B^{s}\right)=1-\Theta_{1} B^{s}-\cdots-\Theta_{Q} B^{s Q}$ is the seasonal moving-averages operator of $Q$ order; $\phi(B)=1-\phi_{1} B-\cdots-\phi_{p} B^{p}$ is the autoregressive operator of $p$ order; $\theta(B)=1-\theta_{1} B-\cdots-\theta_{q} B^{q}$; is the moving-averages operator of $q$ order; and $\Delta_{s}=\left(1-B^{s}\right)$ is the seasonal difference operator. In $\Delta_{s}^{D}=\left(1-B^{s}\right)^{D}, D$ indicates the number of seasonal differences. The Equation (16) is denoted by seasonal autoregressive integrated moving average $(\operatorname{SARIMA})(p, d, q)(P, D, Q)_{s}$

\section{Model Evaluation Criteria}

For the process $A R M A(k, l)$, the Bayesian information criterion (BIC) is given by Equation (17) [24].

$$
B I C(k, l)=\ln \sigma_{k, l}^{2}+(k+l) \frac{\ln N}{N}
$$

where $\sigma_{k, l}^{2}$ is a maximum likelihood estimate of the residual variance of the model with $N$ observations. It seeks to minimize BIC through the adjustments of $k$ and $l$.

For the estimation of the error, Equation (18) is used, where the absolute error module committed in the extermination of the fault location is divided by the total length of the line.

$$
\operatorname{Error}(\%)=100\left|\frac{R_{t}-C_{t}}{T_{t}}\right|
$$

where $R$ is the actual distance value of the fault, $C$ is the value calculated for this distance, and $T$ is the total length of the line. This calculation is performed for all calculated fault distances.

\section{Results}

The proposed method, illustrated by Figure 3, consists of using a discrete wavelet transform DWT in order to decouple the transient signal from the sinusoidal signal characteristic of the transmission line. These decoupled signals are used in ARIMA models to establish mathematical relationships between fault distances and calculated coefficients. The RStudio ${ }^{\circledR}(1.0 .143)$ software is used for the computational implementation of DWT [25] and ARIMA models. 


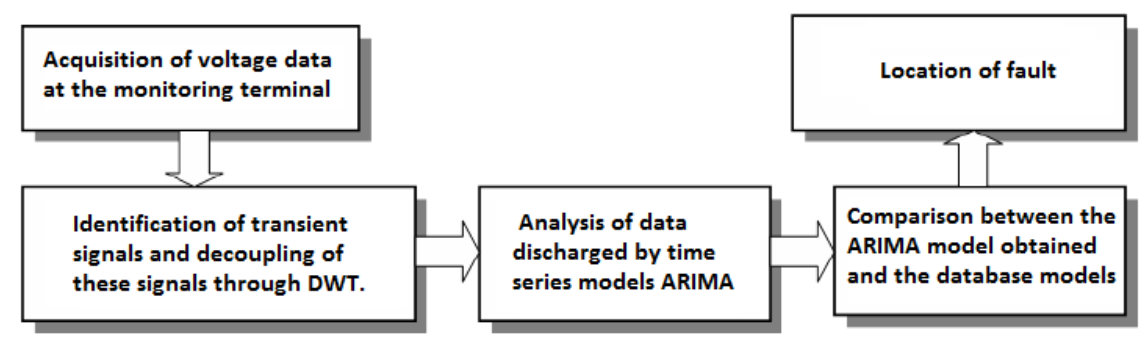

Figure 3. Schematic diagram for fault location with the proposed model. ARIMA: autoregressive integrated moving average; DWT: discrete wavelet transform.

Figure 4 illustrates a fault situation showing the behavior of the disturbance in the three phases that make up the system. Although the fault does not involve phase $C$, it is affected because there is a coupling between the three phases. However, the highest voltage values in the involved phases are evident. The figure further illustrates the decoupled disturbance signal of the characteristic sinusoidal signal of the transmission line.

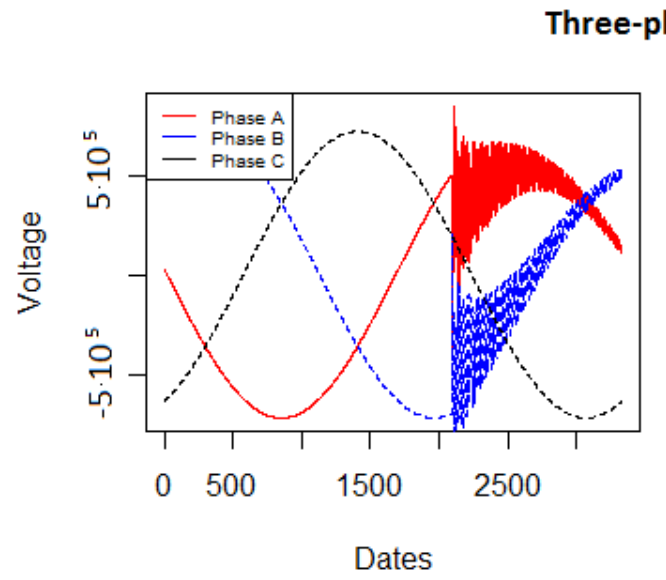

(a)

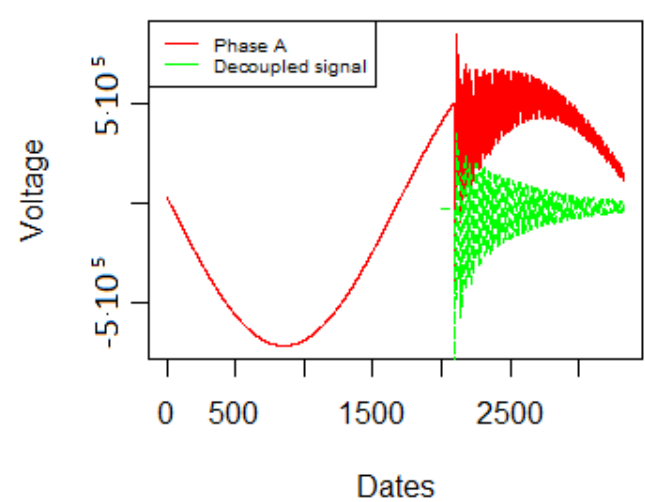

(b)

Figure 4. (a) Voltage signals with incident angle of $90^{\circ}$ and fault resistance of $240 \Omega$ at a distance of $10 \mathrm{~km}$ from the monitoring terminal; (b) Disconnected disturbance signal.

As mentioned, the objective of this work is to relate the distances of occurrences of faults with the curves of ARIMA models. The Table 3 shows some results obtained, showing the distance-coefficient relationship. All cases are two-phase faults with an incidence angle of $90^{\circ}$.

It can be seen from Table 3 that the coefficients of the obtained SARIMA models are equal for the same fault distances. For example, for faults occurring at $10 \mathrm{~km}$, the obtained models are $\operatorname{SARIMA}(2,0,2)(2,0,4)_{19}$ where $\phi_{1}=1.283, \phi_{2}=-0.349, \theta_{1}=-0.344, \theta_{2}=0.028, \Phi_{19}=-1.460$, $\Phi_{38}=-0.918, \Theta_{19}=-1.333, \Theta_{38}=-0.736, \Theta_{57}=0.044$, and $\Theta_{76}=0.073$ in all faults whose angle of incidence is $90^{\circ}$, regardless of the fault resistance values

In Table 4 it should be noted that the traveler wave method presents a smaller error than the other methods when it is at the beginning of the line. According to [26], when traveling waves are used, the main problem is to find the second reverse traveler wave from different disturbance signals. In this case, the proposed model presented a satisfactory result, because as the distance of the fault increases, the relative error becomes smaller than for the other methods. Fault resistances do not influence the behavior of the model, and therefore results are shown for only two resistance values. Figure 5 shows a example of the a fault situation. 
Table 3. Some examples of models obtained.

\begin{tabular}{|c|c|c|c|c|c|c|c|c|}
\hline \multirow{2}{*}{ Term } & \multicolumn{2}{|c|}{$10 \mathrm{~km}$} & \multicolumn{2}{|c|}{$45 \mathrm{~km}$} & \multicolumn{2}{|c|}{$84 \mathrm{~km}$} & \multicolumn{2}{|c|}{155 km } \\
\hline & $20 \Omega$ & $240 \Omega$ & $20 \Omega$ & $240 \Omega$ & $20 \Omega$ & $240 \Omega$ & $20 \Omega$ & $240 \Omega$ \\
\hline$\phi_{1}$ & \multicolumn{2}{|c|}{1.2830} & \multicolumn{2}{|c|}{1.5420} & \multicolumn{2}{|c|}{1.58880} & \multicolumn{2}{|c|}{1.4780} \\
\hline$\phi_{2}$ & \multicolumn{2}{|c|}{-0.3496} & \multicolumn{2}{|c|}{-0.5945} & \multicolumn{2}{|c|}{-0.6358} & \multicolumn{2}{|c|}{-0.5263} \\
\hline$\phi_{3}$ & \multicolumn{2}{|c|}{0.0000} & \multicolumn{2}{|c|}{0.0000} & \multicolumn{2}{|c|}{0.0000} & \multicolumn{2}{|c|}{0.0000} \\
\hline$\theta_{1}$ & \multicolumn{2}{|c|}{-0.3440} & \multicolumn{2}{|c|}{-0.1750} & \multicolumn{2}{|c|}{-0.3322} & \multicolumn{2}{|c|}{-0.6510} \\
\hline$\theta_{2}$ & \multicolumn{2}{|c|}{0.0283} & \multicolumn{2}{|c|}{0.0000} & \multicolumn{2}{|c|}{0.0000} & \multicolumn{2}{|c|}{0.0000} \\
\hline$\Phi_{1}$ & \multicolumn{2}{|c|}{-1.4600} & \multicolumn{2}{|c|}{0.0000} & \multicolumn{2}{|c|}{0.0000} & \multicolumn{2}{|c|}{0.0000} \\
\hline$\Phi_{2}$ & \multicolumn{2}{|c|}{-0.9181} & \multicolumn{2}{|c|}{0.0000} & \multicolumn{2}{|c|}{0.0000} & \multicolumn{2}{|c|}{0.0000} \\
\hline$\Theta_{1}$ & \multicolumn{2}{|c|}{-1.3330} & \multicolumn{2}{|c|}{0.0000} & \multicolumn{2}{|c|}{0.0000} & \multicolumn{2}{|c|}{0.0000} \\
\hline$\Theta_{2}$ & -0 & 7397 & & 000 & & 000 & & 000 \\
\hline$\Theta_{3}$ & & 437 & & 000 & & 000 & & 000 \\
\hline$\Theta_{4}$ & & 730 & & 000 & & 000 & & 000 \\
\hline Constant & & 800 & & .48 & & 400 & & 65 \\
\hline Bayesian information criterion (BIC) & 15,3 & 69.26 & 13,0 & 25.38 & & 4.45 & & 9.99 \\
\hline
\end{tabular}

Table 4. Comparison between models through the Error value (Equation (18)).

\begin{tabular}{ccccc}
\hline Model & $\mathbf{5 - 1 0 ~} \mathbf{~ k m}$ & $\mathbf{2 0 - 4 5} \mathbf{~ k m}$ & $\mathbf{7 0 - 8 4} \mathbf{~ k m}$ & $\mathbf{1 5 5} \mathbf{~ k m}$ \\
\hline Time series & 0.13 & 0.37 & 0.13 & 0.86 \\
Stockwell transformer [26] & 0.07 & 0.10 & 0.65 & - \\
Neural networks [15] & - & 0.75 & - & - \\
Independent components [11] & - & 1.90 & - & - \\
\hline
\end{tabular}

Decoupled disturbance signal and approximate ARIMA model

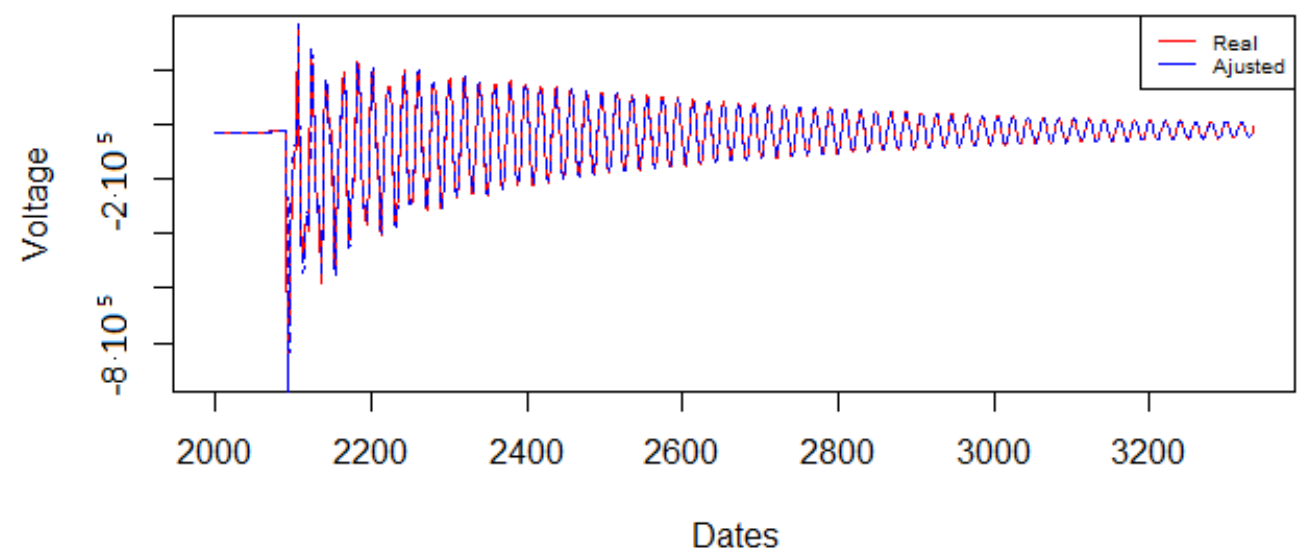

Figure 5. Missing data with distance of $10 \mathrm{~km}$ and with missing resistance of $240 \Omega$.

The auto.arima function of RStudio ${ }^{\circledR}$ (1.0.143) software uses a variation of the Hyndman and Khandakar algorithm presented by [27] that combines unit root tests and minimization of BIC to obtain a model ARIMA.

\section{Discussion and Conclusions}

The proposed method is effective in detecting simulated data changes from different fault locations on the line. However, it is also sensitive to variations in the angles of incidence of the onset of disturbances in sine-wave AC signals. This is particularly true when the fault distance becomes larger in relation to the beginning of the transmission line. With improvements in the algorithm it may be 
possible, in addition to identifying positioning of short circuits in the line, to also identify the angle of said angle of incidence in order to improve the sensitivity of relays used for this type of monitoring.

The algorithm is insensitive to changes in the value of fault resistance. This is in fact an important factor for the adopted methodology, since the fault resistance is highly random and variable, depending on environmental conditions and type and location of the fault. The fault resistance influences the transient signal damping behavior (vertical variations in the Cartesian plane of the signal), but the location of the source of the disturbance is related to the signal oscillation frequency (horizontal variations in the Cartesian plane of the signal).

Another important factor refers to the type of fault in relation to the number of elements involved, whether they are single-phase, two-phase, two-phase ground or three-phase. Another important factor refers to the type of fault in relation to the number of elements involved, that are either single-phase, two-phase, or three-phase. Failure data involving the ground component present greater volatility, since these types of transient waves, besides suffering successive reactions between the point of origin and the line terminals, also undergo refractions. Some of the signals reflected from the terminals exceed the point of origin of the disturbance to the opposite terminal, causing the data to become interlaced. For future works, we suggest evaluating models more sensitive to the heteroscedastic series. A possible alternative to eliminate the data coming from the opposite terminal would be the encapsulation of signal filters in the DWT used for the separation.

Acknowledgments: The authors thank the Federal University Fluminense-UFF and the Federal University of Piauí for their teachers. They are also grateful to the Coordination for the Improvement of Higher Education Personnel-CAPES for post-graduate financial assistance.

Author Contributions: Danilo Pinto Moreira de Souza carried out the computational implementation and the writing of the article; Eliane da Silva Christo contributed to the analysis of the time series, the revision of the text and the orientation of the construction of the work; and Aryfrance Rocha Almeida contributed to the analysis of signals using the wavelet transformer, provided the simulation data used in this work, and contributed to the orientation of the construction of the work.

Conflicts of Interest: The authors declare no conflict of interest.

\section{Abbreviations}

The following abbreviations are used in this manuscript:

$\begin{array}{ll}\text { AR } & \text { autoregressive } \\ \text { ARIMA } & \text { autoregressive integrated moving average } \\ \text { ARMA } & \text { autoregressive moving average } \\ \text { BIC } & \text { Bayesian information criterion } \\ \text { CWT } & \text { continuous wavelet transformer } \\ D W T & \text { discrete wavelet transformer } \\ \text { EPS } & \text { electric power system } \\ \text { GDP } & \text { Gross Domestic Product } \\ M A & \text { moving average } \\ \text { SARIMA } & \text { seasonal autoregressive integrated moving average } \\ \text { TL } & \text { transmission line }\end{array}$

\section{References}

1. Abreu, S.S. Localização de Faltas em Linhas de Transmissão Aéreas pelo Método das Ondas Viajantes Utilizando Filtros Digitais e Transformada Wavelet. Master's Thesis, Programa de Pós-Graduação em Engenharia Elétrica-Universidade Federal de Minas Gerais (PPGEE-UFMG), Belo Horizonte, Brazil, 2005. (In Portuguese)

2. Formiga, D.A. Estimação de Fasores para Proteção de Sistemas Elétricos Baseada em Mínimos Quadrados e Morfologia Matemática; Universidade Federal do Rio Grande do Norte (UFRN): Natal, Brazil, 2012. (In Portuguese) 
3. He, Z.; Liu, X.; Li, X.; Mai, R. A Novel Traveling-Wave Directional Relay Based on Apparent Surge Impedance. IEEE Trans. Power Deliv. 2015, 30, 1153-1161.

4. Rajendra, S.; McLaren, P.G. Travelling-Wave Techniques Applied to the Protection of Teed Circuits: Principle of Travelling Wave Techniques. IEEE Trans. Power Appar. Syst. 1985, 104, 3544-3550.

5. Hänninen, S. Single Phase Earth Faults in High Impedance Grounded Networks: Characteristics, Indication and Location; VTT Technical Research Centre of Finland: Espoo, Finland, 2001.

6. Personal Vázquez, E.; García, A.; Parejo, A.; Larios Marín, D.F.; Biscarri Triviño, F.; León de Mora, C. A Comparison of Impedance-Based Fault Location Methods for Power Underground Distribution Systems. Energies 2016, 9, 1022.

7. Bo, Z.Q.; Weller, G.; Redfern, M.A. Accurate fault location technique for distribution system using fault-generated high-frequency transient voltage signals. IEE Proc. Gener. Transm. Distrib. 1999, 146, 73-79.

8. Souza, D.P.M.; Christo, E.S.; Almeida, A.R. Séries de Fourier Aplicadas à Localizaçao de Faltas em Linhas de Transmissão de Energia Elétrica. In Proceedings of the Anais do III Simpósio de Matemática da Região Sul Fluminense (SIMA/UFF), Rio de Janeiro, Brazil, 23-29 July 2017. (In Portuguese)

9. Souza, D.P.M.; Christo, E.S.; Almeida, A.R. Localização de Faltas em Linhas de Transmissão por Séries Temporais. In Proceedings of the Anais do XXXVII Congresso Nacional de Matemática Aplicada e Computacional (CNMAC/SBMAC), São José dos Campos, Brazil, 19-22 September 2017. (In Portuguese)

10. Silveira, P.M.; Seara, R.; Zürn, H.H. Localização de faltas por ondas viajantes-uma nova abordagem baseada em decomposição Wavelet. In Proceedings of the Anais do XVI Seminário Nacional de Produção e Transmissão de Energia Elétrica-SNPTEE'2001, Campinas, Brazil, 21-26 October 2001. (In Portuguese)

11. Almeida, A.R.; Almeida, O.M.; Silva, J.P.; Alves, M.H.S.; Abreu, F.C.M. Localização de Faltas em Sistemas de Transmissão de Alta Tensão a partir de Registros Oscilográficos Usando Análise de Componentes Independentes. In Proceedings of the Simpósio Brasileiro de Sistemas Elétricos—SBSE, Foz do Iguaçu, Brasil, 22-25 Apirl 2014. (In Portuguese)

12. Paithankar, Y.G.; Bhide, S.R. Fundamentals of Power System Protection; PHI Learning Pvt. Ltd.: New Delhi, India, 2010.

13. Mamede Filho, J.; Mamede, D.R. Proteção de Sistemas Elétricos de Potência; Grupo Gen-LTC: São Paulo, Brasil, 2000; pp. 272-281. (In Portuguese)

14. Marti, J.R. Accurate Modeling of Frequency Dependent Transmission Lines in Electromagnetic Transient Simulations. IEEE Trans. Power Appar. Syst. 1996 1, 1475-1550.

15. Souza, S.C.A.; Braga, A.P.S.; Leão, R.P.S.; Almeida, O.M.A.; Almeida, A.R.; Abreu, F.C.M. Uso de Redes Neurais Artificiais e Transformada de Stockwell na Localização de Faltas em Linhas de Transmissão; Universidade Federal do Ceará (UFC): Fortaleza, Brazil, 2015. (In Portuguese)

16. Souza, T.B.P. Análise de Ondas Viajantes em Linhas de Transmissão para Localização de Faltas: Abordagem via Transformada Wavelet. Master's Thesis, Federal University of Pará (UFPA): Belém, Brazil, 2007. (In Portuguese)

17. Hedman, D.E. Teoria das Linhas de Transmissão-II; Universidade Federal de Santa Maria: Santa Maria, Brazil, 1978. (In Portuguese)

18. Naidu, S.R. Transitórios Eletromagnéticos em Sistemas de Potência. Universidade Federal da Paraíba: João Pessoa, Brazil, 1985. (In Portuguese)

19. Greenwood, A. Electrical Transients in Power Systems; Wiley-Interscience: New York, NY, USA, 1991.

20. Robertson, D.C.; Camps, O.I.; Mayer, J.S.; Gish, W.B. Wavelets and electromagnetic power system transients. IEEE Trans. Power Deliv. 1996, 11, 1050-1056.

21. Chang, H.; Nguyen V.L. Statistical Feature Extraction for Fault Locations in Nonintrusive Fault Detection of Low Voltage Distribution Systems. Energies 2017, 10, 611.

22. Valins, T.F. Relé Digital de Distância Baseado na Teoria de Ondas Viajantes e Transformada Wavelet. Master's Thesis, Escola de Engenharia São Carlos da Universidade de São Paulo, São Carlos, Brazil, 2005. (In Portuguese)

23. Morettin, P.A.; Toloi, C. Modelos para Séries Temporais. In Análise de Séries Temporais; Blucher: Reichenau, Brazil, 2006; pp. 3-70.

24. Choi, B. ARMA Model Identification; Springer Science and Business Media: New York, NY, USA, 2012; pp. 58-87. 
25. Aldrich, E. Wavelets: A Package of Functions for Computing Wavelet Filters, Wavelet Transforms and Multiresolution Analyses; R Package Version 0.3-0; University of Washington: Seattle, WA, USA, 2013.

26. Souza, S.C.A.; Braga, A.P.S.; Almeida, A.R.; Abreu, F.C.M.; Almeida, O.M. Uso da Transformada de Stockwell e ondas Viajantes na Localização de Faltas em Linhas de Transmissão; Universidade Federal do Ceará (UFC): Fortaleza, Brazil, 2014. (In Portuguese)

27. Hyndman, R.J.; Khandakar, Y. Automatic time series for forecasting: The forecast package for R. J. Stat. Softw. 2008, 27, 5-22.

(C) 2017 by the authors. Licensee MDPI, Basel, Switzerland. This article is an open access article distributed under the terms and conditions of the Creative Commons Attribution (CC BY) license (http://creativecommons.org/licenses/by/4.0/). 